Chapter 7

\title{
Decolorization of Dyeing Wastewater Using Polymeric Absorbents - An Overview
}

\author{
George Z. Kyzas, Margaritis Kostoglou, \\ Nikolaos K. Lazaridis and Dimitrios N. Bikiaris \\ Additional information is available at the end of the chapter
}

http://dx.doi.org/10.5772/52817

\section{Introduction}

The exact amount of dyes produced in the world is not known. Exact data on the quantity of dyes discharged in the environment are also not available. It is assumed that a loss of $1-2 \%$ in production and $1-10 \%$ loss in use (after being garment) are a fair estimate [1]. For reactive dyes, this figure can be about $10-20 \%$ due to low fixation. Due to large-scale production and extensive application, synthetic dyes can cause considerable environmental pollution and are serious health-risk factors. Although, the growing impact of environmental protection on industrial development promotes the development of eco-friendly technologies, reduced consumption of freshwater and lower output of wastewater [1], the release of important amounts of synthetic dyes to the environment causes public concern, legislation problems and is a serious challenge to environmental scientists.

Globally, accessing to freshwater is becoming more acute every day. In the dyeing of textile materials, water is used firstly in the form of steam to heat the treatment baths, and secondly to enable the transfer of dyes to the fibers. Cotton, which is the world's most widely used fiber, is also the substrate that requires the most water in its processing [2]. The dyeing and rinsing of $1 \mathrm{~kg}$ of cotton with reactive dyes demands from 70 to $150 \mathrm{~L}$ water, 0.6 to $0.8 \mathrm{~kg}$ $\mathrm{NaCl}$ and anywhere from 30 to $60 \mathrm{~g}$ dyestuff. More than $80,000 \mathrm{tn}$ of reactive dyes are produced and consumed each year, making it possible to estimate the total pollution caused by their use. After the dyeing is completed, the various treatment baths are drained out, including the first dye bath, which has a very high salt concentration, is heavily coloured and contains a substantial load of organic substances [2]. One solution to this problem consists in mixing together all the different aqueous effluents, then concentrating the pollution and reusing the water either as rinsing water or as processing water, depending on the treatment 
selected (either nanofiltration or reverse osmosis for the membrane processes). These treatments apply only to very dilute dye baths [2]. This is generally not the case of the first dye baths recovered which are the most heavily polluted ones. The wastewater produced by a reactive dyeing contains [2,3]: (i) hydrolyzed reactive dyes not fixed on the substrate, representing $20-30 \%$ of the reactive dyes applied (on average $2 \mathrm{~g} / \mathrm{L}$ ) (this residual amount is responsible for the coloration of the effluents and cannot be recycled); (ii) dyeing auxiliaries or organic substances, which are non-recyclable and responsible for the high BOD/COD of the effluents; (iii) textile fibres, and (iv) 60-100 g/L electrolyte, essentially $\mathrm{NaCl}$ and $\mathrm{Na}_{2} \mathrm{CO}_{3}$, which is responsible for the very high saline content of the wastewater.

In addition, these effluents exhibit a $\mathrm{pH}$ of $10-11$ and a high temperature $\left(50-70{ }^{\circ} \mathrm{C}\right)$. The legal regulations respecting the limit values for the release of wastewater are changing and are becoming increasingly severe, including the limits with respect to salinity.

A typical effluent treatment is broadly classified into preliminary, primary, secondary, and tertiary stages $[4,5]$. The preliminary stage includes equalization and neutralization. The primary stage involves screening, sedimentation, flotation, and flocculation. The secondary stage reduces the organic load and facilitates the physical/chemical separation (biological oxidation). The tertiary stage is focused on decolorization. In the latter, adsorption onto various materials can be broadly used to limit the concentration of colour in effluents [3].

\subsection{Dyes}

The first synthetic dye, Mauveine was discovered by the Englishman, William Henry Perkin by chance in 1856 . Since then the dyestuffs industry has matured [6].

A dye or dyestuff is a coloured compound that can be applied on a substrate. With few exceptions, all synthetic dyes are aromatic organic compounds. A substrate is the material to which a colorant is applied by one of the various processes of dyeing, printing, surface coating, and so on. Generally, the substrate includes textile fibers, polymers, foodstuffs, oils, leather, and many other similar materials [7].

Not all coloured compounds are dyestuffs because a coloured compound may not have suitable application on a substrate. For example, a chemical such as copper sulphate, which is coloured, finds no application on any substrate. If it is applied on a substrate, it will not have retaining power on the substrate and for this reason copper sulphate cannot be termed as a dye. On the other hand, congo red, a typical organic coloured compound. When it applied to cotton under suitable conditions can be retained on this natural fibre and due to this finds useful application on this fibre. It is termed as a dyestuff [7].

In the field of chemistry, chromophores and auxochromes are the major component element of dye molecule. Dyes contain an unsaturated group basically responsible for colour and designated it as chromophore ("chroma" means colour and "phore" means bearer) (Table 1). Auxochromes ("Auxo" means augment) are the characteristic groups which intensify colour and/or improve the dye affinity to substrate [7] (Table 1). 


\begin{tabular}{|c|c|c|c|}
\hline Chromophore group & Name & Auxogroup & Name \\
\hline$-\mathrm{N}=\mathrm{N}-$ & Azo & $-\mathrm{NH}_{2}$ & Amino \\
\hline$-\mathrm{N}=\mathrm{N}^{+}-\mathrm{O}^{-}$ & Azoxy & $-\mathrm{NHCH}_{3}$ & Methyl amino \\
\hline$-\mathrm{N}=\mathrm{N}-\mathrm{NH}$ & Azoamino & $-\mathrm{N}\left(\mathrm{CH}_{3}\right)_{2}$ & Dimethyl amino \\
\hline$-\mathrm{N}=\mathrm{O}, \mathrm{N}-\mathrm{OH}$ & Nitroso & $-\mathrm{SO}_{3} \mathrm{H}$ & Sulphonic acid \\
\hline$>C=O$ & Carbonyl & $-\mathrm{OH}$ & Hydroxy \\
\hline$>\mathrm{C}=\mathrm{C}<$ & Ethenyl & $-\mathrm{COOH}$ & Carboxylic acid \\
\hline$>C=S$ & Thio & $-\mathrm{Cl}$ & Chloro \\
\hline$-\mathrm{NO}_{2}$ & Nitro & $-\mathrm{CH}_{3}$ & Methyl \\
\hline \multirow[t]{4}{*}{$>\mathrm{C}=\mathrm{NH}_{1}>\mathrm{C}=\mathrm{N}-$} & Azomethine & $-\mathrm{OCH}_{3}$ & Methoxy \\
\hline & & $-\mathrm{CN}$ & Cyano \\
\hline & & $-\mathrm{COCH}_{3}$ & Acetyl \\
\hline & & $-\mathrm{CONH}_{2}$ & Amido \\
\hline
\end{tabular}

Table 1. Names of chromophore and auxochrome groups of dyes

To further examine the interactions between dyes and substrates, the classification of dyes is required. It is very important to know the chemistry of the dyes in dyeing effluents, in order to synthesize a suitable adsorbent with the appropriate functional group. Hunger et al [7] mentioned that dyes are classified in two methods. The main classification is related to the chemical structure of dyes and particularly considering the chromophoric structure presented in dye molecules. Another type of classification is based on their usage or applying. The classification of dyes by usage or application is the most important system adopted by the Colour Index (CI). Briefly [8]:

Reactive dyes. These dyes form a covalent chemical bond with fiber is ether or ester linkage under suitable conditions. Majority of reactive dyes contains azo that includes metallized azo, triphendioxazine, phthalocyanine, formazan, and anthraquinone. The molecular structures of these dyes are much simpler than direct dyes. They also produce brighter shades than direct dyes. Reactive dyes are primarily used for dyeing and printing of cotton fibers.

Direct dyes. In the presence of electrolytes, these anionic dyes are water-soluble in aqueous solution. They have high affinity to cellulose fibers. Most of the dyes in this class are polyazo compounds, along with some stilbenes, phthalocyanines, and oxazines. To improve wash fastness, frequently chelations with metal (such as copper and chromium) salts are applied to the dyestuff. Also, their treatment with formaldehyde or a cationic dye-complexing resin.

Disperse dyes. These are substantially water insoluble nonionic dyes applied to hydrophobic fibers from microfine aqueous dispersion. They are used predominantly on polyester, polyamide, polyacrylonitrile, polypropylene fibers to a lesser, it is used to dye nylon, cellulose acetate, and acrylic fibers. Chemical structures of dyes are mainly consisted of azo and an- 
thraquinonoid groups, having low molecular weight and containing groups which aid in forming stable aqueous dispersions.

Vat dyes. These dyes are water insoluble and can apply mainly to cellulose fiber by converting them to their leuco compounds. The latter was carried out by reduction and solubilization with sodium hydrosulphite and sodium hydroxide solution, which is called "vatting process". The main chemical/structural groups of vat dyes are anthraquinone and indigoid.

Sulfur dyes. They are water insoluble and are applied to cotton in the form of sodium salts by the reduction process using sodium sulphide as the reducing agent under alkaline conditions. The low cost and good wash fastness properties of dyeing makes these dyes economic attractive.

Cationic (Basic dyes). These dyes are cationic and water soluble. They are applied on paper, polyacrylonitrile, modified nylons, and modified polyesters. In addition, they are used to apply with silk, wool, and tannin-mordant cotton when brightness shade was more necessary than fastness to light and washing.

Acid dyes. They are water soluble anionic dyes and are applied on nylon, wool, silk, and modified acrylics. Moreover, they are used to dye paper, leather, inkjet printing, food, and cosmetics.

Solvent dyes. They are water insoluble, but solvent soluble, dyes having deficient polar solubility group for example sulfonic acid, carboxylic acid or quaternary ammonium. They are used for colouring plastics, gasoline, oils, and waxes.

Mordant dyes. These dyes have mordant dyeing properties with good quality in the presence of certain groups in the dye molecule. These groups are capable to hold metal residuals by formation of covalent and coordinate bonds involving a chelate compound. The salts of aluminium, chromium, copper, cobalt, nickel, iron, and tin are used as mordant that their metallic salts.

Aside from mentioned above, there are azoic dyes, ingrain dyes, pigment [6,7,9]. Comparative analysis of dye classes are presented in Table 2:

\begin{tabular}{llll}
\hline \multicolumn{1}{c}{ Class } & \multicolumn{1}{c}{ Fiber type } & \multicolumn{1}{c}{ Chemistry } & \multicolumn{1}{c}{ Characteristics } \\
\hline Acid & $\begin{array}{l}\text { nylon, wool, silk, } \\
\text { paper ink, leather }\end{array}$ & $\begin{array}{l}\text { Azo, anthraquinone, azine, } \\
\text { xanthene, nitro, nitroso }\end{array}$ & $\begin{array}{l}\text { - Anionic compounds } \\
\text { - Highly water soluble } \\
\end{array}$ \\
\hline Azoic & $\begin{array}{l}\text { cotton, rayon, } \\
\text { cellulose acetate, } \\
\text { polyester }\end{array}$ & azo & - Contain azo group \\
& leather, wool, silk paper, & cyanine, azo, azine, & - Metallic compounds \\
modified nylon, & triarylmethane, xanthen, & - Highly water soluble \\
& polyacrylonitrile, & &
\end{tabular}




\begin{tabular}{|c|c|c|c|}
\hline Class & Fiber type & Chemistry & Characteristics \\
\hline & polyester, inks & $\begin{array}{l}\text { acridine, oxazine, } \\
\text { anthraquinone }\end{array}$ & \\
\hline Direct & $\begin{array}{l}\text { cotton, paper, rayon, } \\
\text { leather, nylon }\end{array}$ & $\begin{array}{l}\text { azo, phthalocyanine, stilbene, } \\
\text { nitro, benzodifuranone }\end{array}$ & $\begin{array}{l}\text { - Anionic compounds } \\
\text { - Highly water soluble } \\
\text { - Poor wet fastness. }\end{array}$ \\
\hline Disperse & $\begin{array}{l}\text { polyester, polyamide, } \\
\text { acetate, acrylic, plastics }\end{array}$ & $\begin{array}{l}\text { azo, anthraquinone, styryl, } \\
\text { nitro, benzodifuranone }\end{array}$ & $\begin{array}{l}\text { - Colloidal dispersion } \\
\text { - Very low water solubility } \\
\text { - Good wet fastness }\end{array}$ \\
\hline Mordant & $\begin{array}{l}\text { wool, leather, } \\
\text { anodized aluminium }\end{array}$ & azo, anthraquinone & $\begin{array}{l}\text { - Anionic compounds } \\
\text { - Water soluble } \\
\text { - Good wet fastness }\end{array}$ \\
\hline Reactive & $\begin{array}{l}\text { cotton, wool, } \\
\text { silk, nylon }\end{array}$ & $\begin{array}{l}\text { azo, anthraquinone, } \\
\text { phthalocyanine, formazan }\end{array}$ & $\begin{array}{l}\text { - Highly water soluble } \\
\text { - Good wet fastness. }\end{array}$ \\
\hline
\end{tabular}

Table 2. Classification of dyes and their properties

\subsection{Decolorization techniques}

Methods of dye wastewater treatment have been reported [11-14]. Also, fungal and bacterial decolorization methods have been reviewed [15-18]. There are several reported methods for the removal of pollutants from effluents. The technologies can be divided into three categories: biological, chemical and physical [11]. All of them have advantages and drawbacks. Because of the high cost and disposal problems, many of these conventional methods for treating dye wastewater have not been widely applied at large scale in the textile and paper industries. At the present time, there is no single process capable of adequate treatment, mainly due to the complex nature of the effluents $[19,20]$. In practice, a combination of different processes is often used to achieve the desired water quality in the most economical way. A literature survey shows that research has been and continues to be conducted in the areas of combined adsorption-biological treatments in order to improve the biodegradation of dyestuffs and minimize the sludge production.

Biological treatment is often the most economical alternative when compared with other physical and chemical processes. Biodegradation methods such as fungal decolorization, microbial degradation, adsorption by (living or dead) microbial biomass and bioremediation systems are commonly applied to the treatment of industrial effluents because many microorganisms such as bacteria, yeasts, algae and fungi are able to accumulate and degrade different pollutants $[14,16,17]$. However, their application is often restricted because of technical constraints. Biological treatment requires a large land area and is constrained by sensitivity toward diurnal variation as well as toxicity of some chemicals, and less flexibility in design and operation [21]. Biological treatment is incapable of obtaining satisfactory color elimination with current conventional biodegradation processes [11]. Moreover, although 
many organic molecules are degraded, many others are recalcitrant due to their complex chemical structure and synthetic organic origin [22]. In particular, due to their xenobiotic nature, azo dyes are not totally degraded.

Chemical methods include coagulation or flocculation combined with flotation and filtration, precipitation-flocculation with $\mathrm{Fe}(\mathrm{II}) / \mathrm{Ca}(\mathrm{OH})_{2}$, electroflotation, electrokinetic coagulation, conventional oxidation methods by oxidizing agents (ozone), irradiation or electrochemical processes. These chemical techniques are often expensive, and although the dyes are removed, accumulation of concentrated sludge creates a disposal problem. There is also the possibility that a secondary pollution problem will arise because of excessive chemical use. Recently, other emerging techniques, known as advanced oxidation processes, which are based on the generation of very powerful oxidizing agents such as hydroxyl radicals, have been applied with success for pollutant degradation. Although these methods are efficient for the treatment of waters contaminated with pollutants, they are very costly and commercially unattractive. The high electrical energy demand and the consumption of chemical reagents are common problems.

Different physical methods are also widely used, such as membrane-filtration processes (nanofiltration, reverse osmosis, electrodialysis) and adsorption techniques. The major disadvantage of the membrane processes is that they have a limited lifetime before membrane fouling occurs and the cost of periodic replacement must thus be included in any analysis of their economic viability. In accordance with the very abundant literature data, liquid-phase adsorption is one of the most popular methods for the removal of pollutants from wastewater since proper design of the adsorption process will produce a high-quality treated effluent. This process provides an attractive alternative for the treatment of contaminated waters, especially if the adsorbent is inexpensive and does not require an additional pre-treatment step before its application. Adsorption is a well known equilibrium separation process and an effective method for water decontamination applications [23]. Adsorption has been found to be superior to other techniques for water re-use in terms of initial cost, flexibility and simplicity of design, ease of operation and insensitivity to toxic pollutants. Adsorption also does not result in the formation of harmful substances.

\subsection{Adsorption}

Adsorption techniques for wastewater treatment have become more popular in recent years owing to their efficiency in the removal of pollutants, which are difficulty treated with biological methods. Adsorption can produce high quality water while also being a process that is economically feasible. Decolourisation is a result of two mechanisms (adsorption and ion exchange) and is influenced by many factors including dye/adsorbent interaction, adsorbent's surface area, particle size, temperature, $\mathrm{pH}$ and contact time.

Physical adsorption occurs when weak interparticle bonds exist between the adsorbate and adsorbent. Examples of such bonds are van der Waals, hydrogen and dipole-dipole. In the majority of cases physical adsorption is easily reversible [24]. Chemical adsorption occurs when strong interparticle bonds are present between the adsorbate and adsorbent due to an exchange of electrons. Examples of such bonds are covalent and ionic bonds. Two means 
that are useful to be developed are "chemisorption" and "physisorption". Chemisorption is a kind of adsorption which involves a chemical reaction between the surface and the absorbate. New chemical bonds are generated at the adsorbent surface. Examples include macroscopic phenomena that can be very obvious, like corrosion, and subtler effects associated with heterogeneous catalysis. The strong interaction between the adsorbate and the substrate surface creates new types of electronic bonds. In contrast with chemisorption is physisorption, which leaves the chemical species of the adsorbate and surface intact. It is conventionally accepted that the energetic threshold separating the binding energy of "physisorption" from that of "chemisorptions" is about $0.5 \mathrm{eV}$ per adsorbed species. Chemisorption is deemed to be irreversible in the majority of cases [24]. Suzuki [25] covers the role of adsorption in water environmental processes and also the development of newer adsorbents to modernise the treatment systems. Most adsorbents are highly porous materials. As the pores are generally very small, the internal surface area is orders of magnitude greater than the external area.

Separation occurs because either the differences in molecular mass, shape or polarity causes some molecules to be held more strongly on the surface than others or the pores are too small to admit large molecules [25]. However, amongst all the adsorbent materials proposed, activated carbon is the most popular for the removal of pollutants from wastewater $[26,27]$. In particular, the effectiveness of adsorption on commercial activated carbons (CAC) for removal of a wide variety of dyes from wastewaters has made it an ideal alternative to other expensive treatment options [26]. Because of their great capacity to adsorb dyes, CAC are the most effective adsorbents. This capacity is mainly due to their structural characteristics and their porous texture which gives them a large surface area, and their chemical nature which can be easily modified by chemical treatment in order to increase their properties. However, activated carbon presents several disadvantages [27]. It is quite expensive, the higher the quality, the greater the cost, non-selective and ineffective against disperse and vat dyes. The regeneration of saturated carbon is also expensive, not straightforward, and results in loss of the adsorbent. The use of carbons based on relatively expensive starting materials is also unjustified for most pollution control applications [28]. This has led many workers to search for more economic adsorbents.

\subsubsection{Polymeric adsorbents (chitosan)}

The majority of commercial polymers and ion exchange resins are derived from petroleumbased raw materials using chemical processes that are not always safe or environmental friendly. Today, there is growing interest in developing natural low-cost alternatives to synthetic polymers [29]. Chitin (Figure 1), found in the exoskeleton of crustaceans, the cuticles of insects, and the cells walls of fungi, is the most abundant aminopolysaccharide in nature [30]. This low-cost material is a linear homopolymer composed of b(1-4)-linked N-acetyl glucosamine. It is structurally similar to cellulose, but it is an aminopolymer and has acetamide groups at the C-2 positions in place of the hydroxyl groups. The presence of these groups is highly advantageous, providing distinctive adsorption functions and conducting modification reactions. The raw polymer is only commercially extracted from marine crustaceans pri- 
marily because a large amount of waste is available as a by-product of food processing [30]. Chitin is extracted from crustaceans (shrimps, crabs, squids) by acid treatment to dissolve the calcium carbonate followed by alkaline extraction to dissolve the proteins and by a decolorization step to obtain a colourless product [30].

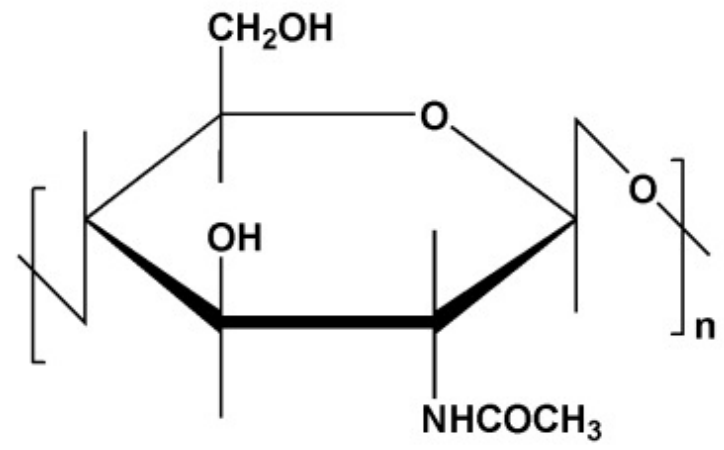

Figure 1. Chemical structures of chitin.

Since the biodegradation of chitin is very slow in crustacean shell waste, accumulation of large quantities of discards from processing of crustaceans has become a major concern in the seafood processing industry. So, there is a need to recycle these by-products. Their use for the treatment of wastewater from other industries could be helpful not only to the environment in solving the solid waste disposal problem, but also to the economy. However, chitin is an extremely insoluble material. Its insolubility is a major problem that confronts the development of processes and uses of chitin [30], and so far, very few large-scale industrial uses have been found. More important than chitin is its derivative, chitosan.

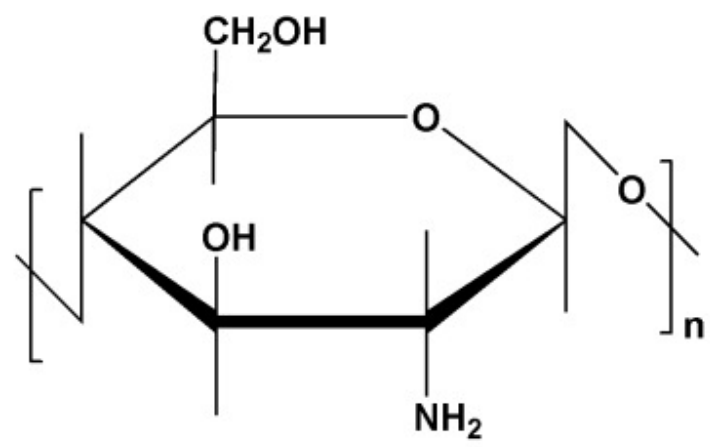

Figure 2. Chemical structures of chitosan. 
Partial deacetylation of chitin results in the production of chitosan (Figure 2), which is a polysaccharide composed by polymers of glucosamine and $\mathrm{N}$-acetyl glucosamine (Figure 3 ).

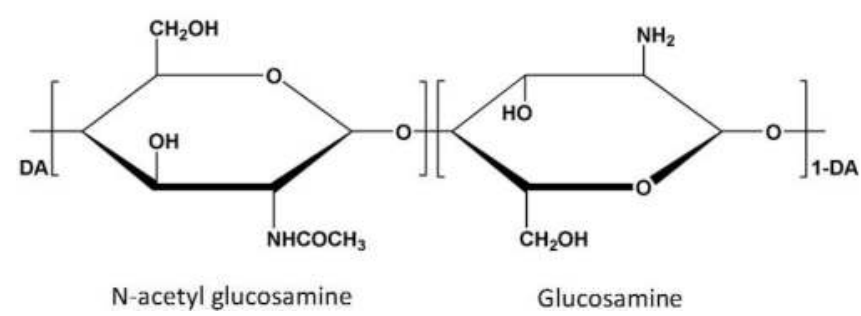

Figure 3. Chemical structures of commercial chitosan composed of $\mathrm{N}$-acetyl glucosamine.

The "chitosan label" generally corresponds to polymers with less than $25 \%$ acetyl content. The fully deacetylated product is rarely obtained due to the risks of side reactions and chain depolymerization. Copolymers with various extents of deacetylation and grades are now commercially available. Chitosan and chitin are of commercial interest due to their high percentage of nitrogen compared to synthetically substituted cellulose. Chitosan is soluble in acid solutions and is chemically more versatile than chitin or cellulose. The main reason for this is undoubtedly its appealing intrinsic properties, as documented in a recent review [30], such as biodegradability, biocompatibility, film-forming ability, bioadhesivity, polyfunctionality, hydrophilicity and adsorption properties. Most of the properties of chitosan can be related to its cationic nature [30], which is unique among abundant polysaccharides and natural polymers. These numerous properties lead to the recognition of this polyamine as a promising raw material for adsorption purposes.

The elevated interest in chitin and chitosan is reflected by an increase in the number of articles published and talks given on this topic. Currently, these polymers and their numerous derivatives as described in reviews $[29,31]$ are widely used in pharmacy, medicine, biotechnology, chemistry, cosmetics and toiletries, food technology, and the textile, agricultural, pulp and paper industries and other fields such as oenology, dentistry and photography. The potential industrial use of chitosan is widely recognized. These versatile materials are also widely used in clarification and water purification, water and wastewater treatment as coagulating, flocculating and chelating agents. However, despite a large number of publication on the use of chitosan for pollutant recovery, the research failed to find practical applications on the industrial scale: this aspect will be discussed later.

\section{Synthesis of adsorbents}

\subsection{Grafting reactions}

The basic idea of modifications is to make various changes in chitosan structure to enhance its properties (capacity, resistance etc). In particular, several researchers have proposed cer- 
tain mofidifications in chitosan backbone to improve its adsorption capacity. These modifications are realized with grafting reactions [32-38]. The modifications can improve chitosan's removal performance and selectivity for dyes, alter the physical and mechanical properties of the polymer, control its diffusion properties and decrease the sensitivity of adsorption to environmental conditions. Many scientists suggested chemical grafting specific ligands [39,40]. However the only class for which chitosan [37] has low affinity is basic (cationic) dyes. To overcome this problem, the use of N-benzyl mono- and disulfonate derivatives of chitosan is suggested to enhance its cationic dye hydrophobic adsorbent properties and to improve its selectivity $[32,33,41]$. These derivatives could be used as hydrophobic adsorbents in acidic media without any cross-linking reactions. To enhance and further develop the high potentials of chitosan, it is necessary to add/introduce chemical substituents at a specific position in a controlled manner [37]. This chemical derivatization promotes new adsorption properties in particular towards basic dyes in acidic medium or reactive/acid dyes in basic medium. Another study deals with the enzymatic grafting of carboxyl groups onto chitosan as a mean to confer the ability to adsorb basic dyes on beads [37]. The presence of new functional groups on the surface of beads results in increased surface polarity and density of adsorption sites and hence improved adsorption selectivity for the target dye. Other studies showed that the ability of chitosan to selectively adsorb dyes could be further improved by chemical derivatization. Novel chitosan-based materials with long aliphatic chains are developed by reacting chitosan with high fatty acids and glycidyl moieties [36]. In this way, these products could be used as effective adsorption materials for both anionic and cationic dyes. Other researchers suggested the use of cyclodextrin-grafted chitosan derivatives as new chitosan derivatives for the removal of dyes [34,35,42]. These materials are characterized by a rate of adsorption and a global efficiency greater than that of the parent chitosan polymer [35].

\subsection{Cross-linking reactions}

The pure form of chitosan powders (raw) tends to present some disadvantages such as unsatisfactory mechanical properties and poor heat resistance. Another important limitation of the pure form is its solubility in acidic media and therefore it cannot be used as an insoluble adsorbent under these conditions (except after physical and chemical modification). The main technique to overcome these limitations is to transform the raw polymer into a form whose physical characteristics are more attractive. So, cross-linked beads have been developed and proposed. After cross-linking, these materials maintain their properties and original characteristics [43], particularly their high adsorption capacity, although this chemical modification results in a decrease in the density of free amine groups at the surface of the adsorbent in turn lowering polymer reactivity towards metal ions [44,45]. The cross-linking agent is very important. Therefore many researchers studied the chitosan behaviour prepared with different cross-linkers, such as glutaraldehyde (GLA), tripolyphosphate sodium (TPP), epichlorydrine (EPI), ethylene glycol diglycidyl ether (EGDE), etc [46-49]. The change in adsorption capacity was confirmed; the results showed that the chitosan-EPI beads presented a higher adsorption capacity than GLA and EGDE $[46,47]$. They reported that these materials can be used for the removal of reactive, direct and acid dyes. It was found that $1 \mathrm{~g}$ 
chitosan adsorbed 2498, 2422, 2383 and $1954 \mathrm{mg}$ of various reactive dyes (Reactive Blue 2, Reactive Red 2, Direct Red 81 and Acid Orange 12, respectively) [49]. As a comparison, it is specified that the adsorption capacities of commercially activated carbon for reactive dyes generally vary from 280 to $720 \mathrm{mg} / \mathrm{g}$. Another advantage of EPI is that it does not eliminate the cationic amine function of the polymer, which is the major adsorption site to attract the anionic dyes during adsorption [47]. The cross-linking with GLA (formation of imine functions) or EDGE decreases the availability of amine functions for the complexation of dyes. With a high cross-linking ratio the uptake capacity decreases drastically. Among the conditions of the cross-linking reaction that have a great impact on dye adsorption are the chemical nature of the cross-linker, as mentioned above, but also the extent of the reaction. In general, the adsorption capacity depends on the extent of cross-linking and decreases with an increase in cross-linking density. When chitosan beads were cross-linked with GLA under heterogeneous conditions, it was found that the saturation adsorption capacity of reactive dyes on cross-linked chitosan decreased exponentially from 200 to $50 \mathrm{mg} / \mathrm{g}$ as the extent of cross-linking increased from 0 to $1.5 \mathrm{~mol} \mathrm{GLA} / \mathrm{mol}$ of amine. This is because of the restricted diffusion of molecules through the polymer network and reduced polymer chain flexibility. Also the loss of amino-binding sites by reaction with aldehyde is another major factor in this decrease. However, the cross-linking step was necessary to improve mechanical resistance, to enhance the resistance of material against acid, alkali and chemicals, and also to increase the adsorption abilities of chitosan. According to literature [46-49], the adsorption capacity of non cross-linked beads was greater than that of cross-linked beads in the same experimental conditions. The materials, mainly cross-linked using GLA, have been also proposed as effective dye removers by several researchers [34,43]. The reaction of chitosan with GLA leads to the formation of imine groups, in turn leading to a decrease in the number of amine groups, resulting in a lowered adsorption capacity, especially for dyes adsorbed through ion-exchange mechanisms. In heterogeneous conditions, chitosan (solid state) was simply mixed with GLA solution, while in homogeneous conditions chitosan was mixed with GLA solution after being dissolved in acetic acid solution. An optimum aldehyde/amine ratio was determined for dye adsorption that depends on the type of cross-linking (water-soluble or solid-state solution) operation. The initial increase in dye adsorption was attributed to the low levels of cross-linking in the precipitates preventing the formation of closely packed chain arrangements without any great reduction in the swelling capacity. This increase in adsorption was interpreted in terms of the increases in hydrophilicity and accessibility of complexing groups as a result of partial destruction of the crystalline structure of the polymer by cross-linking under homogeneous conditions. At higher levels of cross-linking, the precipitates had lower swelling capacities, and hence lower accessibility because of the more extensive three-dimensional network and also because of its more hydrophobic character with increased GLA content. In general, the adsorption capacity increased greatly at low degrees of substitution but decreased with increasing substitution. This phenomenon is interpreted in terms of increased hydrophilicity caused by the destruction of the crystalline structure at low cross-linking densities, while this can be associated with an accompanying decrease in active sites, accessibility, and swellability of the adsorbent by increasing the level of cross-linking. Furthermore, it is noted that cross-linking can 
change the crystalline nature of chitosan, as suggested by the XRD diffractograms. After the cross-linking reaction, there was a small increase in the crytallinity of the chitosan beads and also increased accessibility to the small pores of the material.

\section{Adsorption conditions}

\subsection{Equilibrium}

\subsection{1. $\mathrm{pH}$}

The $\mathrm{pH}$ of the dye solution plays an important role in the whole adsorption process and particularly on the adsorption capacity; influences the surface charge of the adsorbent, the degree of ionization of the material present in the solution, the dissociation of functional groups on the active sites of the adsorbent, and the chemistry of dye solution. It is important to indicate that while the adsorption on activated carbon was largely independent of the $\mathrm{pH}$, the adsorption of dyes on chitosan was controlled by the acidity of the solution. pH affects the surface charge of the adsorbent. Chitosan is a weak base and is insoluble in water and organic solvents, however, it is soluble in dilute aqueous acidic solution ( $\mathrm{pH} \sim 6.5$ ), which can convert the glucosamine units into a soluble form $\mathrm{R}_{-} \mathrm{NH}_{3}{ }^{+}$. Chitosan is precipitated in alkaline solution or in the presence of polyanions and forms gels at lower $\mathrm{pH}$. Its $\mathrm{pKa}$ depends on the deacetylation degree, the ionic strength and the neutralization of amine groups. In practice pKa lies within 6.5-6.7 for fully neutralized amine functions [50]. So, chitosan is polycationic in acidic medium: the free amino groups are protonated and the polymer becomes fully soluble and this facilitates electrostatic interaction between chitosan and the negatively charged anionic dyes. This cationic property, especially in the case of anionic dyes, depending on the charge and functions of the dye under the corresponding experimental conditions will influence the adsorption procedure [51]. In the literature, the ability of the anionic dyes to adsorb onto chitosan beads is often attributed to the surface charge which depends on the $\mathrm{pH}$ of the operating batch system, as mentioned. Dye adsorption occurred through electrostactic attraction on protonated amine groups and numerous researchers concluded that the influence of the $\mathrm{pH}$ confirmed the essential role of electrostatic interactions between the chitosan and the target dye. For example, chitosan had a positively charged surface below $\mathrm{pH}=6.5$ (point of zero potential) [52], and reducing the $\mathrm{pH}$ increased the positivity of the surface, thus making the adsorption process $\mathrm{pH}$ sensitive. Decreasing the $\mathrm{pH}$ makes more protons available to protonate the amine group of chitosan with the formation of a large number of cationic amines. This results in increased dye adsorption by chitosan due to increased electrostatic interactions. Differences in $\mathrm{pH}$ of the solution have also been reported to influence the dye adsorption capacity of chitosan and its mechanism [44,45]. They noted that, at low $\mathrm{pH}$, chitosan's free amino groups are protonated, causing them to attract anionic dyes, demonstrating that $\mathrm{pH}$ is one of the most important parameters controlling the adsorption process. Some researchers $[32,33,53]$ also found that the adsorption capacity of cationic dyes on chitosan-grafted materials was strongly affected by the $\mathrm{pH}$ of solution and was generally significantly decreased by increasing the $\mathrm{pH}$. $\mathrm{pH}$ is also known to affect the struc- 
tural stability of dye molecules (in particular the dissociation of their ionizable sites), and therefore their colour intensity. As a result, the dye molecule has high positive charge density at a low $\mathrm{pH}$. This indicates that the deprotonation (or protonation) of a dye must be taken into consideration. If the dyes to be removed are either weakly acidic or weakly basic, then the $\mathrm{pH}$ of the medium affects their structure and adsorption. Initial $\mathrm{pH}$ also influences the solution chemistry of the dyes: hydrolysis, complexation by organic and/or inorganic ligands, redox reactions, and precipitation are strongly influenced by $\mathrm{pH}$, and on the other side strongly influence speciation and the adsorption capacity of the dyes. Some useful structural characteristics must be pointed out, as given below:

The free amine groups in chitosan are much more reactive and effective for chelating pollutants than the acetyl groups in chitin. There is no doubt that amine sites are the main reactive groups for (anionic) dye adsorption, though hydroxyl groups (especially in the C-3 position) may contribute to adsorption. Almost all functional properties of chitosan depend on the chain length, charge density and charge distribution and much of its potential as adsorbent is effected by its cationic nature and solution behaviour. However, at neutral $\mathrm{pH}$, about $50 \%$ of total amine groups remain protonated and theoretically available for the adsorption of dyes. The existence of free amine groups may cause direct complexation of dyes co-existing with anionic species, depending on the charge of the dye. As the $\mathrm{pH}$ decreases, the protonation of amine groups increases together with the efficiency. The optimum $\mathrm{pH}$ is frequently reported in the literature to be around $\mathrm{pH} 2-4$. Below this range, usually a large excess of competitor anions limits adsorption efficiency. This competitor effect is the subject of many studies aiming to develop materials that are less sensitive to the presence of competitor anions and to the $\mathrm{pH}$ of the solution, as described in the next two paragraphs.

It is not really the total number of free amine groups that must be taken into account but the number of accessible free amine groups. There are several explanations for this. The availability of amine groups is controlled by two important parameters: (i) the crystallinity of polymer, and (ii) the diffusion properties of dyes. It is known that some of the amine sites on chitosan are included in both the crystalline area and in inter or intramolecular hydrogen bonds. Moreover the residual crystallinity of the polymer may control the accessibility to adsorption sites. The deacetylation degree also controls the fraction of free amine groups available for interactions with dyes. Indeed, the total number of free amine groups is not necessarily accessible for dye uptake. Actually, rather than the fraction or number of free amine groups available for dye uptake, it would be better to consider the number of accessible free amine groups. It is also concluded that the hydrogen bonds linked between monomer units of the same chain (intramolecular bonds) and/or between monomer units of different chains (intermolecular bonds) decrease their reactivity. The weakly porous structure of the polymer and its residual crystallinity are critical parameters for the hydratation and the accessibility to adsorption sites.

\subsubsection{Isotherms}

Adsorption properties and equilibrium data, commonly known as adsorption isotherms, describe how pollutants interact with adsorbent materials and so, are critical in optimizing the 
use of adsorbents [31]. In order to optimize the design of an adsorption system to remove dye from solutions, it is important to establish the most appropriate correlation for the equilibrium curve. An accurate mathematical description of equilibrium adsorption capacity is indispensable for reliable prediction of adsorption parameters and quantitative comparison of adsorption behaviour for different adsorbent systems (or for varied experimental conditions) within any given system. Adsorption equilibrium is established when the amount of dye being adsorbed onto the adsorbent is equal to the amount being desorbed. It is possible to depict the equilibrium adsorption isotherms by plotting the concentration of the dye in the solid phase versus that in the liquid phase. The distribution of dye molecule between the liquid phase and the adsorbent is a measure of the position of equilibrium in the adsorption process and can generally be expressed by one or more of a series of isotherm models [54-58]. The shape of an isotherm may be considered with a view to predicting if a sorption system is "favourable" or "unfavourable". The isotherm shape can also provide qualitative information on the nature of the solute-surface interaction. In addition, adsorption isotherms have been developed to evaluate the capacity of chitosan materials for the adsorption of a particular dye molecule. They constitute the first experimental information, which is generally used as a convenient tool to discriminate among different materials and thereby choose the most appropriate one for a particular application in standard conditions. The most popular classification of adsorption isotherms of solutes from aqueous solutions has been proposed by Giles et al. [57,58]. Four characteristic classes are identified, based on the configuration of the initial part of the isotherm (i.e., class S, L, H, C). The Langmuir class (L) is the most widespread in the case of adsorption of dye compounds from water, and it is characterized by an initial region, which is concave to the concentration axis. Type L also suggests that no strong competition exists between the adsorbate and the solvent to occupy the adsorption sites. However, the $\mathrm{H}$ class (high affinity) results from extremely strong adsorption at very low concentrations giving rise to an apparent intercept on the ordinate. The H-type isotherms suggest the uptake of pollutants by materials through chemical forces rather than physical attraction. There are several isotherm models available for analyzing experimental data and for describing the equilibrium of adsorption, including Langmuir, Freundlich, Langmuir-Freunldich, BET, Toth, Temkin, Redlich-Peterson, Sips, Frumkin, Harkins-Jura, Halsey, Henderson and Dubinin-Radushkevich isotherms. These equilibrium isotherm equations are used to describe experimental adsorption data. The different equation parameters and the underlying thermodynamic assumptions of these models often provide insight into both the adsorption mechanism, and the surface properties and affinity of the adsorbent. Therefore, it is important to establish the most appropriate correlation of equilibrium curves to optimize the condition for designing adsorption systems. Various researchers have used these isotherms to examine the importance of different factors on dye molecule sorption by chitosan. However, the two most frequently used equations applied in solid/liquid systems for describing sorption isotherms are the Langmuir [55] and the Freundlich [56] models and the most popular isotherm theory is the Langmuir one which is commonly used for the sorption of dyes onto chitosan.

The majority of researchers found significant correlations between dye concentration and the dye-binding capacity of polymeric adsorbents and particularly chitosan $[3,41,53]$. The 
amount of the dye adsorbed onto chitosan increased with an increase in the initial concentration of dye solution if the amount of adsorbent was kept unchanged. This is due to the increase in the driving force of the concentration gradient with the higher initial dye concentration. In most cases, at low initial concentration the adsorption of dyes by chitosan is very intense and reaches equilibrium very quickly. This indicates the possibility of the formation of monolayer coverage of the dye molecules at the outer interface of the chitosan. At a fixed adsorbent dose, the amount of dye adsorbed increases with the increase of dye concentration in solution, but the percentage of adsorption decreased. In other words, the residual concentration of dye molecules will be higher for higher initial dye concentrations. In the case of lower concentrations, the ratio of initial number of dye moles to the available adsorption sites is low and subsequently the fractional adsorption becomes independent of initial concentration $[3,41,46,47,49,52,53]$. At higher concentrations, however, the number of available adsorption sites becomes lower and subsequently the removal of dyes depends on the initial concentration. At the high concentrations, it is not likely that dyes are only adsorbed in a monolayer at the outer interface of chitosan. As a matter of fact, the diffusion of exchanging molecules within chitosan particles may govern the adsorption rate at higher initial concentrations. In another theory, it is claimed that adsorption rate may diminish with an increase in dye concentration [34].This could be ascribed to the accompanying increase in dye aggregation and/or depletion of accessible active sites on the material.

Generally speaking, the adsorption of pollutants increases with the increase in temperature, because high temperatures provide a faster rate of diffusion of adsorbate molecules from the solution to the adsorbent [31,41]. However, it is well known that temperature plays an important role in adsorption onto activated carbon, generally having a negative influence on the amount adsorbed. The adsorption of organic compounds (including dyes) is an exothermic process and the physical bonding between the organic compounds and the active sites of the carbon will weaken with increasing temperature. Also with the increase of temperature, the dye solubility also increases, the interaction forces between the solute and the solvent become stronger than those between solute and adsorbent, consequently the solute is more difficult to adsorb. Both of these features are consistent with the order of Langmuir adsorption capacity. The adsorption of dyes by chitosan is also usually exothermic: an increase in the temperature leads to an increase in the dye adsorption rate, but diminishes total adsorption capacity $[3,41,53]$. However, these effects are small and normal wastewater temperature variations do not significantly affect the overall decolorization performance [59]. In addition, the adsorption process is not usually operated at high temperature, because this would increase operation costs. The increase in temperature affects not only the solubility of the dye molecule (its solubility increases), but also the adsorptive potential of the material (its adsorption capacity increases). Both effects work in the same direction causing an increase of cost operation in the batch system. In general, this could be confirmed by the thermodynamic parameters. An increase in temperature is also followed by an increase in the diffusivity of the dye molecule, and consequently by an increase in the adsorption rate if diffusion is the rate-limiting step. Temperature could also influence the desorption step and consequently the reversibility of the adsorption equilibrium. So, the temperature (and its variation) is an important factor affecting chitosan adsorption and investigations of this pa- 
rameter offer interesting results, albeit often contradictory. The usual increase in adsorption may be attributed to the fact that on increasing temperature, a greater number of active sites is generated on the polymer beads because of an enhanced rate of protonation/deprotonation of the functional groups on the beads. The fact that adsorption of dyes on chitosan increases with higher temperature can be surprising. Other authors concluded that an increase in temperature leads to a decrease in the amount of adsorbed dye at equilibrium since adsorption on chitosan is exothermic $[60,61]$.

\subsection{Kinetics - Modelling}

The conventional approach to quantify the batch adsorption process is the empirical fitting based on the dependence between the global adsorption rate and the driving force for adsorption i.e. the difference between the actual and the equilibrium adsorbate concentration. This dependence can be a linear one but in most cases is taken as quadratic. The parameters extracted from the fitting procedure may be appropriate to represent the experimental data, but they do not have any direct physical meaning (although some researchers relate them to an hypothetical diffusion coefficient). In addition, this type of empirical modelling cannot be extended to describe more complicated process geometries than the simple batch one. A phenomenological approach based on fundamental principles) is needed, in order to develop models with parameters with physical meaning. This type of models can be extended to be used for the design of processes of engineering interest (like fixed bed adsorption) and improve the understanding of the adsorbent structure in line with its interaction with the adsorbate.

The phenomenological approach to the batch adsorption is well-known. Kyzas et al [41] made an attempt for the description of the derivation of the models, of the inherent assumptions and of how several simplified models used in literature are hooked to the general approach. The description of the approach will be made for a general porous solid and then the adjustment to the particular structure of the chitosan derivatives will be presented. The actual difficulty in the modeling of the adsorption process for porous adsorbents is not its physics but its geometry in micro-scale. For extensive discussion on the physics of adsorption process please see other works $[62,63]$. The physics is well-understood in terms of the occurring processes: (i) diffusion of the adsorbate in the liquid, (ii) adsorption-desorption between the liquid and solid phase, and (iii) surface diffusion of the adsorbate. See a simple schematic on the phenomena occurring in a pore in Figure 4.

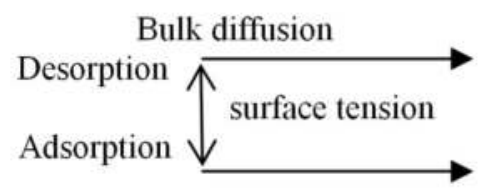

Figure 4. Phenomena occurring in pore scale 
On the other hand, the actual shape of the geometry, in which the above phenomena occur, is completely unknown. Recently, several reconstructions or tomographic techniques have been developed for the 3-D digitization of the internal structure of porous media [64]. This digitized structure can be used to solve the equations describing the prevailing phenomena. The above approach is extremely difficult (still inapplicable for the size of pores met in adsorption applications), time consuming and its use is restricted to porous media development applications. A more effective approach is needed for the purpose of adsorption process design. So, the classical approach of "homogenizing" the corresponding partial differential equations and transferring the lack of knowledge of the geometry to the values of the physical parameters of the problem is given below. In the adsorbent particle phase, the adsorbate can be found both as solute in the liquid, filling the pores of the particle (concentration $\mathrm{C}$ in $\mathrm{kg} / \mathrm{m}^{3}$ ) and adsorbed on the solid phase (concentration $\mathrm{q}$ in $\mathrm{kg}$ adsorbate $/ \mathrm{kg}$ adsorbent). The "homogeneous" equations for the evolution of $\mathrm{C}$ and $\mathrm{q}$ inside a spherical adsorbent particle of radius $\mathrm{R}$, are the following:

$$
\begin{aligned}
\varepsilon_{p} \frac{\partial C}{\partial t} & =\frac{1}{r^{2}} \frac{\partial}{\partial r} r^{2} D_{p} \frac{\partial C}{\partial r}-\rho_{p} G(C, q) \\
\frac{\partial \mathrm{q}}{\partial \mathrm{t}} & =\frac{1}{\mathrm{r}^{2}} \frac{\partial}{\partial \mathrm{r}} \mathrm{r}^{2} \mathrm{D}_{\mathrm{s}} \frac{\partial \mathrm{q}}{\partial \mathrm{r}}-\mathrm{G}(\mathrm{C}, \mathrm{q})
\end{aligned}
$$

where $\mathrm{t}$ is the time, $\mathrm{r}$ is the radial direction, $\varepsilon_{\mathrm{p}}$ the porosity of the particle, $\mathrm{Q}_{\mathrm{p}}$ the density of the particle $\left(\mathrm{kg}\right.$ adsorbent $\left./ \mathrm{m}^{3}\right), \mathrm{D}_{\mathrm{p}}$ is the liquid phase diffusivity of the adsorbate and $\mathrm{D}_{\mathrm{s}}$ is the corresponding surface diffusivity. The diffusivity $\mathrm{D}_{\mathrm{p}}$ for a given pair of adsorbate-fluid depends only on the temperature, whereas the diffusivity $D_{s}$ depends both on the type of adsorbent and on $q$ also (apart from their dependence on geometry). For particles with nonuniform structure the parameters $\mathrm{D}_{\mathrm{p}}, \mathrm{D}_{\mathrm{s}}, \varepsilon_{\mathrm{p}}, \mathrm{Q}_{\mathrm{p}}$ are functions of $\mathrm{r}$ but this case will not be considered here. The function $\mathrm{G}(\mathrm{C}, \mathrm{q})$ denotes the rate of the adsorption-desorption process. The boundary conditions for the above set of equations are:

i) mass transfer from the solution to particle:

$$
\mathrm{k}_{\mathrm{m}}\left(\mathrm{C}_{\mathrm{b}}-\mathrm{C}\right)=-\mathrm{D}_{\mathrm{p}}\left(\frac{\partial \mathrm{C}}{\partial \mathrm{r}}\right)_{\mathrm{r}=\mathrm{R}} \quad \text { at } \mathrm{r}=\mathrm{R}
$$

where $C_{b}$ is the concentration of the adsorbate in the bulk solution, and $k_{m}$ is the mass transfer coefficient from the bulk solution to the particle.

ii) spherical symmetry:

$$
\left(\frac{\partial \mathrm{C}}{\partial \mathrm{r}}\right)=\left(\frac{\partial \mathrm{q}}{\partial \mathrm{r}}\right)=0 \quad \text { at } \mathrm{r}=\mathrm{R}
$$


Having values for the initial concentrations of adsorbate in the particle and for the bulk concentration $C_{b}$, the above mathematical problem can be solved for the functions $C(r, t)$ and $q(r, t)$. The above model is the so-called non-equilibrium adsorption model. Models of this structure are used in large scale solute transport applications (e.g. soil remediation), where the phenomena are of different scale from the present application [65]. In the case of adsorption by small particles, the adsorption-desorption process is much faster than the diffusion, leading to an establishment of a local equilibrium (which can be found by setting $G(C, q)=0$ and corresponds to the adsorption isotherm $\mathrm{q}=\mathrm{f}(\mathrm{C})$ ). In the present case, the local

$$
q=\frac{q_{m} b C^{1 / n}}{1+b C^{1 / n}}
$$

where $\mathrm{q}_{\mathrm{m}}$ and $\mathrm{b}$ corresponds to $\mathrm{Q}_{\max }$ and $\mathrm{K}_{\mathrm{LF}}$, respectively of L-F model.

In the limit of very fast adsorption-desorption kinetics it can be shown by a rigorous derivation that the mathematical problem can be transformed to the following:

$$
\begin{gathered}
\frac{\partial \mathrm{q}}{\partial \mathrm{t}}=\frac{1}{\mathrm{r}^{2}} \frac{\partial}{\partial \mathrm{r}} \mathrm{r}^{2} \mathrm{D}(\mathrm{C}) \frac{\partial \mathrm{q}}{\partial \mathrm{r}} \\
\left(\frac{\partial \mathrm{q}}{\partial \mathrm{r}}\right)_{\mathrm{r}=0}=0 \\
k_{m}\left(C_{b}-C\right)=\rho_{p} D_{p}\left(\frac{\partial q}{\partial r}\right)_{r=R}
\end{gathered}
$$

An additional assumption considered in the above derivation is that the amount of the adsorbate found in the liquid phase in the pores of the particle is insignificant compared to the respective amount adsorbed on the solid phase (i.e. $\varepsilon_{\mathrm{p}} \mathrm{C}<<\mathrm{Q}_{\mathrm{p}} \mathrm{q}$ ). This assumption always holds, as it can be easily checked by recalling the definition of the adsorption process.

The concentration $\mathrm{C}$ in eqs 6,8 can be found by inverting the relation $\mathrm{q}=\mathrm{f}(\mathrm{C})$. The diffusivity $\mathrm{D}$ is an overall diffusivity, which combines the bulk and surface diffusivity and is given by the relation:

$$
D=D_{s}+\frac{D_{p}}{\rho_{p} f^{\prime}(C)}
$$

where the prime denotes the differentiation of a function with respect to its argument. The average concentration of the adsorbed species (dye molecules) can be computed by the relation: 


$$
\mathrm{q}_{\text {ave }}=\frac{3}{\mathrm{R}^{3}} \int_{0}^{\mathrm{R}} \mathrm{qr}^{2} \mathrm{dr}
$$

In case of batch experiments the concentration of the solute in bulk liquid $\mathrm{C}_{\mathrm{b}}$ decreases due to its adsorption; so, the evolution of the $\mathrm{C}_{\mathrm{b}}$ must be taken into account by the model. The easier way to do this is to consider a global mass balance of the adsorbate:

$$
\mathrm{C}_{\mathrm{b}}=\mathrm{C}_{\mathrm{b}_{0}}-\frac{\mathrm{m}}{\mathrm{V}} \mathrm{q}_{\mathrm{ave}}
$$

where $C_{b o}$ is the initial value of $C_{b}$; $m$ is the total mass of the adsorbent particles; $V$ is the volume of the tank.

Let us now refer to the several analytical or simple numerical techniques used in literature for the above problem and explain under which conditions they can be employed. In the case of an overall diffusion coefficient $\mathrm{D}$ with no concentration dependence (which implies (i) constant $\mathrm{D}_{\mathrm{s}}$ and (ii) zero $\mathrm{D}_{\mathrm{p}}$ or linear adsorption isotherm) and a linear adsorption isotherm, the complete problem is linear and it can be solved analytically. The mathematical problem for the case of surface diffusion is equivalent to the homogeneous diffusion or solid diffusion model used by several authors [66]. The complete solution is given by Tien [54], but their simplified versions [67], which ignore external mass transfer and/or the solute concentration reduction through equation 13 (i.e. assuming an infinite liquid volume), are extensively used in the literature with topic of dye adsorption [68]. In case of constant diffusivity, and non-linear adsorption isotherm (which implies no pore diffusion and it is usually used in adsorption from liquid phase studies), several techniques based on the fundamental solutions of the diffusion equation can be used [66,69]. In general, the partial differential equation is transformed to an integro-differential equation for the average concentration $\mathrm{q}_{\mathrm{ave}}$ (dimensionality reduction).

Another class of approximation methods, which can be used in any case (but with a questionable success for non-linear problems), is the so-called Linear Driving Force model (LDF model) [70]. The concentration profile in the particle is approximated by a simple function (usually polynomial with two or three terms) and using this, the partial differential equation problem can be replaced by an expression for the evolution of $\mathrm{q}_{\mathrm{ave}}$. This method is not appropriate for use in batch adsorption studies, but it has been proven to be successful in cases like fixed bed adsorption. In these cases, where the solution of equation 8 in several positions along the case of adsorption bed is required, LDF approximation is very useful. In cases, where no simplifications are possible and high accuracy is required, one has to resort to numerical techniques. A widely used approach is the collocation discretization of the spatial dimension, which is very efficient due to the use of higher order approximation. However, its advantage can be completely lost for the case of very rapid (or even discontinuous) changes of the parameters inside the particle. In order to be able to extend our approach to 
non-uniform particles, a typical finite difference discretization (permitting arbitrarily dense grid) is performed in the spatial dimension.

The model for adsorption by chitosan derivatives and how it fits to the above general adsorption model will be discussed next. The chitosan particles are homogeneous consisting of swollen polymeric material. The basic (cationic) dyes are diffused in the swollen polymer phase and are incorporated (adsorbed) on the polymer with the interaction of the amino and hydroxyl groups [71]. In the case of reactive (anionic) dyes, the incorporation step is due to strong electrostatic attraction [72]. The kinetics of the whole process have been modeled in two distinct ways: based on diffusion [73] or based on the global chelation (or in general immobilization) reaction [75]. In the present study, the two modeling approaches are unified by assuming a composite mechanism of diffusion in the water phase, adsorption-desorption on the polymeric structure and diffusion on the polymeric structure (transition from one adsorption site to another). The system of equations for the above model is exactly the same, but with different meaning for some symbols. In particular, $\varepsilon_{\mathrm{p}}$ is the liquid volume fraction of the particle, $\mathrm{D}_{\mathrm{p}}$ is again the liquid phase diffusivity of the adsorbate, and $\mathrm{D}_{\mathrm{s}}$ is the diffusivity associated to the transition rate from one adsorption site to another. The function $\mathrm{G}(\mathrm{C}, \mathrm{q})$ denotes the rate of the reversible adsorption process (chelation reaction or electrostatic attraction). The rest of the model development is exactly the same with that of the general porous solid, assuming that the form of the adsorption-desorption equilibrium isotherm is that of extended Langmuir.

A very useful application to experimental data of the model described above is developed by our research team [41]. The dye adsorbents were grafted chitosan beads with sulfonate groups (abbreviated as Ch-g-Sulf), N-vinylimido groups (abbreviated as Ch-g-VID), and non-grafted beads (abbreviated as $\mathrm{Ch}$ ). The tests were carried out both for reactive and basic dyes.

Although chitosan has a gel-like structure, the water molecules can be found in relatively large regions, which can be characterized as pores with diameters of 30-50 nm for the pure chitosan. The dye molecules which are diffused through these pores, are adsorbed-desorbed on the pore walls and finally are diffused (transferred) from one adsorption site to the other. All these phenomena are included to the kinetic model described in this study. There are two unknown parameters, namely pore and surface diffusivity $\left(D_{p}\right.$ and $\left.D_{s}\right)$, which must be found from the kinetic data. The simultaneous determination of both parameters requires experimental data of intraparticle adsorbate concentration, which are not easily available. Thus, the kinetic data can be fitted to the infinite pairs of $D_{p}$ and $D_{s}$ by keeping the value of the one parameter fixed and calculating the value of the other one that fits the experimental kinetic data.

At the first stage of model employment, the surface diffusion is ignored (setting $D_{s}=0$ ) and the pore diffusivity is calculated and fitted to the experimental kinetic data. In order to make the diffusion coefficients comparative, it is necessary to estimate the diffusivity of each dye in the water $\left(D_{w}\right)$ at the corresponding temperatures. The diffusivity in water are calculated according to the Wilke-Chang correlation (molecular radius can be found by employing codes like the BioMedCAChe 5.02 program by Fujitsu). 
The key point of the procedure developed here is to compare the effective pore diffusivity $\left(D_{p}\right)$ of the dye with its diffusivity in the water $\left(D_{w}\right)$. This relation has the well known form [75]:

$$
\mathrm{D}_{\mathrm{p}}=\mathrm{D}_{\mathrm{w}} \frac{\varepsilon}{\tau}
$$

where $\varepsilon$ is the porosity (water volume fraction), and $\tau$ is the tortuosity of the adsorbent particle. Given that the structure of the particle $(\varepsilon, \tau)$ does not depend on the temperature, and assuming that the pure pore diffusion with no any other type of interactions is responsible for the solute transfer in the adsorbent particle, the temperature's dependence of $D_{p}$ must follow the temperature's dependence of $D_{p}$.

Basic dye. From all the combinations of dye-adsorbent examined up to now, the only one in which $D_{p}$ follows the temperature dependence of $D_{w}$ is the combination of basic dye-Ch (adsorption of basic dye onto non-grafted chitosan). The value $D_{p} / D_{w}=\tau / \varepsilon$ is found to be temperature independent, suggesting that the actual transport mechanism is the pore diffusion with no specific interactions between adsorbent and solute $(\tau / \varepsilon$ is found to be about 12$)$. Indeed, Ch has amino and hydroxyl groups in its molecule, but smaller in number compared to that of grafted chitosan. So, the relatively weak interactions between dye and adsorbent (hydrogen bonding, van der Waals forces, pi-pi interactions, chelation) [72,76] do not drastically affect the transportation/diffusion of dye. Taking into account that $\varepsilon$ for chitosan derivatives ranges between 0.4 and $0.6, \tau$ is calculated to be about 6 ; this is a reasonable value located between the generally proposed value $(\tau=3)$ and the values that holds for microporous solids as activated carbon $(\tau>10)$ [77]. On the contrary, the higher values of the $D_{p}$, which were found in the case of grafted chitosan derivatives, indicate that the surface diffusion mechanism takes part. So, the fitting procedure must be repeated using the $D_{p}$ values calculated (as an approximation assuming similar geometric structures) for the non-grafted chitosan (Ch) and searching for the $\mathrm{D}_{\mathrm{s}}$ values that fits these data. Of course, a slight decrease of $\tau / \varepsilon$ versus temperature, which was found for $\mathrm{Ch}$, suggests that some surface diffusion is still presented, but given the approximate nature of analysis, it is reasonable to ignore it. The surface diffusivity extracted from the experimental data appears to exhibit smaller temperature dependence than pore diffusivity. In surface diffusivity, the increase with temperature is related to the enhancement of the thermal motion of the adsorbed molecules (proportional to the absolute temperature), whereas in pore diffusivity the latter is related to the decrease of the water viscosity. The surface diffusivity also increases with grafting as the density of the adsorption sites increases. It is due to the fact that the larger density of adsorption sites corresponds to the smaller site-to-site distance in the chitosan backbone, and consequently to the higher probability of transition from one site to another.

Reactive dye. The situation (mechanism of diffusion) is different in the case of the reactive dyes. It would be helpful to observe the relation of the structure of this type of dye and the respective structure of the adsorbents used. The dye is composed of sulfonate groups [8], and the adsorbents contain amino groups (the higher basicity of adsorbent, the stronger protonation occurs at acidic conditions) [75]. So, the main adsorption mechanism of reactive 
dyes onto chitosan is based on the strong electrostatic interactions between dissociated sulfonate groups of the dye and protonated amino groups of the chitosan. Many studies confirm that the above process is favored under acidic conditions, where the total "charge" of chitosan adsorbent is more positive (due to the stronger protonation of amino groups at acidic $\mathrm{pH}$ values) $[78,79]$.

Proposing our diffusion concept, it is obvious from the experimental data that: (i) the temperature's dependence of the coefficients $D_{p}$ suggests that the transport mechanism is not simply a pure diffusion through the pores, and (ii) the small values of $D_{p}$ versus $D_{w}$ set questions about the existence of surface diffusivity. The above observations are compatible to the nature of interactions between the reactive dye and the adsorbent, which is described above. The strong electrostatic interaction in the adsorption sites inhibits the surface diffusion. Moreover, the electrostatic forces have a relatively large region of action. Using as reference the non-grafted chitosan (Ch), the existence of charges of opposite sign the pore walls creates a surface charge gradient in addition to the adsorbate gradient in the adsorbent particle. This charge gradient drags the oppositely charged dye molecules inside the particle and leads to enhanced effective pore diffusivity. This fact could completely explain the increase of diffusivity related with the grafting groups (the more positively charged grafted groups, the stronger attraction of negatively charged dye molecule). As the density of the adsorption sites increases, the charge density in the particle increases, leading to higher effective pore diffusivity values. The temperature's dependence of this electrostatically facilitated diffusion process is weaker than that of the pure diffusion process. However, the opposite phenomenon is occurred in the case of sulfonate-chitosan derivative (Ch-g-Sulf), where the surface charge is of the same sign as that of the dye molecule, inhibiting the diffusion process. The above concept of the adsorption process of reactive dyes on chitosan derivatives suggests the development of models that take into account explicitly the electrostatic interaction between dye and adsorbent, instead of considering them only by the modification, which they create to the effective pore diffusivity $D_{p}$. Conclusively, by employing the phenomenological model based on the pair pore-surface diffusion for the transport of the dye in the adsorbent particle information about the actual mechanism of adsorption and on interaction between adsorbent and adsorbate can be extracted.

\section{Desorption conditions and Reuse}

Chitosan adsorbents present considerable advantages such as their high adsorption capacity, selectivity and also the facility of regeneration. The regeneration of the adsorbent may be crucially important for keeping the process costs down and to open the possibility of recovering the pollutant extracted from the solution. For this purpose, it is desirable to desorb the adsorbed dyes and to regenerate the chitosan derivative for another cycle of application. Generally, the regeneration of saturated chitosan for non-covalent adsorption can be easily achieved by using an acid solution as the desorbing agent. Researchers proposed to desorb the dye from the beads by changing the $\mathrm{pH}$ of the solution [52,53] and they showed that the beads could be reused five times without any loss of mechanical or chemical efficacy. The 
optimum $\mathrm{pH}$ of desorption was determined to be the contrast of the optimum of adsorption [53]. Another study has shown the desorption capability of chitosan even at the same $\mathrm{pH}$ conditions as those of adsorption [3]. In the same study, 10 cycles were achieved with no significant loss of re-adsorption capacity ( 5\% loss between $1^{\text {st }}$ and last cycle).

\section{Conclusions}

The treatment of industrial dyeing effluent that contains the large number of organic dyes by adsorption process, using easily available low-cost adsorbents, is an interesting alternative to the traditionally available aqueous waste processing techniques (chemical coagulation/flocculation, ozonation, oxidation, photodegradation, etc.). Undoubtedly, low-cost adsorbents offer a lot of promising benefits for commercial purposes in the future. The distribution of size, shape, and volume of voids species in the porous materials is directly related to the ability to perform the adsorption application. The comparison of adsorption performance of different adsorbents depend not only on the experimental conditions and analytical methods (column, reactor, and batch techniques) but also the surface morphology of the adsorbent, surface area, particle size and shape, micropore and mesopore volume, etc. Many researchers have made comparison between the adsorption capacities of the adsorbents, but they have nowhere discussed anything about the role of morphology of the adsorbent, even in case of the inorganic material where it plays a major role in the adsorption process. The $\mathrm{pH}$ value of the solution is an important factor which must be considered during the designing of the adsorption process. The $\mathrm{pH}$ has two kinds of influences on dye: (i) an effect on the solubility, and (ii) speciation of dye in the solution (it depends on dye class). It is well known that surface charge of adsorbent can be modified by changing the $\mathrm{pH}$ of the solution. The high adsorption of cationic or acidic dyes at higher $\mathrm{pH}$ may be due to the surface of adsorbent becomes negative, which enhances the positively charged dyes through electrostatic force of attraction and vice versa in case of anionic or basic dyes. In case of chitosan-based materials, the literature reveals that maximum removal of dyes from aqueous waste can be achieved in the $\mathrm{pH}$ range of 2-4. However, physical and chemical processes such as drying, autoclaving, cross-linking reactions, or contacting with organic or inorganic chemicals proposed for improving the sorption capacity and the selectivity. The production of chitosan also involves a chemical deacetylation process. Chitosan is characterized by its easy dissolution in many dilute mineral acids, with the remarkable exception of sulfuric acid. It is thus necessary to stabilize it chemically for the recovery of dyes in acidic solutions. Several methods have been developed to reinforce chitosan stability. The advantage of chitosan over other polysaccharides is that its polymeric structure allows specific modifications without too many difficulties. The chemical derivatization of the polymer by grafting new functional groups onto the chitosan backbone may be used to increase the adsorption efficiency, to improve adsorption selectivity, and also to decrease the sensitivity of adsorption environmental conditions. It is interesting to note the relationships between physicochemical properties and/or sources of chitosan and the dye-binding properties. Most of the properties and potential of chitosan as adsorbent can be related to its cationic nature, which is 
unique among abundant polysaccharides and natural polymers, and its high charge density in solution.

The common adsorbent, commercially available activated carbon has good capacity for the removal of pollutants. But its main disadvantages are the high price of treatment and difficult regeneration, which increases the cost of wastewater treatment. Thus, there is a demand for other adsorbents, which are of inexpensive material and do not require any expensive additional pretreatment step. However, there is no direct answer to the question which adsorbent is better: chitosan (raw material, preconditioned chitosan, grafted or cross-linked chitosans) or activated carbons? The best choice depends on the dye and it is impossible to determine a correlation between the chemical structure of the dye and its affinity for either carbon or chitosan. Each product has advantages and drawbacks. In addition, comparisons are difficult because of the scarcity of information and also inconsistencies in data presentation.

\section{Author details}

George Z. Kyzas ${ }^{1,2 *}$, Margaritis Kostoglou², Nikolaos K. Lazaridis ${ }^{2}$ and Dimitrios N. Bikiaris ${ }^{2}$

*Address all correspondence to: georgekyzas@gmail.com

1 Department of Oenology and Beverage Technology, Technological Educational Institute of Kavala, Greece

2 Department of Chemistry, Division of Chemical Technology, Aristotle University of Thessaloniki, Greece

\section{References}

[1] Forgacs, E, Cserhati, T, \& Oros, G. (2004). Removal of synthetic dyes from wastewaters: a review,. Environ. Int., 30, 953-971.

[2] Allègre, C, Moulin, P, Maisseu, M, \& Chrabit, F. (2006). Treatment and reuse of reactive dyeing effluents. J. Membrane Sci., 269, 15-34.

[3] Kyzas, G. Z, Kostoglou, M, Vassiliou, A. A, \& Lazaridis, N. K. (2011). Treatment of real effluents from dyeing reactor: Experimental and modeling approach by adsorption onto chitosan. Chem. Eng. J., 168, 577-585.

[4] Vandenivere, P. C, Bianchi, R, \& Vestraete, W. (1998). Treatment and reuse of wastewater from textile wet-processing industry: review of emerging technologies. $J$. Chem. Technol. Biot., 72, 289-302. 
[5] Neill, O, Hawkes, C, Hawkes, F. R, Lourenço, D. L, Pinheiro, N. D, \& Delée, H. M. W. (1999). Colour in textile effluents-sources, measurement, discharge consents and simulation: a review. J. Chem. Technol. Biot. , 74, 1009-1018.

[6] Hunger, K. (2003). Industrial dyes: Chemistry, properties, applications. Germany: Wiley-VCH;

[7] Rangnekar, D. W, \& Singh, P. P. (1980). An introduction to synthetic dyes. Bombay: Himalaya;

[8] Zollinger, H. (1987). Color Chemistry. Syntheses, Properties, and Applications of Organic Dyes and Pigments. New York: Weinhem- VCH;

[9] Shenai, V. A. (1977). Technology of textile processing volume II: Chemistry of dyes and principles of dyeing. Bombay: Sevak;

[10] Pokhrel, D, \& Viraraghavan, T. (2004). Treatment of pulp and paper mill wastewatera review. Sci. Total Environ., 333, 37-58.

[11] Robinson, T, Mcmullan, G, Marchant, R, \& Nigam, P. (2001). Remediation of dyes in textile effluent: a critical review on current treatment technologies with a proposed alternative. Bioresour. Technol., 77, 247-255.

[12] Slokar, Y. M, Majcen, Le, \& Marechal, A. (1998). Methods of decoloration of textile wastewaters. Dyes Pigments, 37, 335-356.

[13] Delee, W, O'Neill, C, Hawkes, F. R., \& Pinheiro, H. M. (1998). Anaerobic treatment of textile effluents: a review. J. Chem. Technol. Biot., 73, 323-335.

[14] Banat, I. M, Nigam, P, Singh, D, \& Marchant, R. (1996). Microbial decolorization of textile-dye-containing effluents: a review. Bioresour. Technol., 58, 217-227.

[15] Pearce, C. I, Lloyd, J. R, \& Guthrie, J. T. (2003). The removal of colour from textile wastewater using whole bacterial cells: a review. Dyes Pigments, 58, 179-196.

[16] Mcmullan, G, Meehan, C, Conneely, A, Kirby, N, Robinson, T, Nigam, P, Banat, I. M, Marchant, R, \& Smyth, W. F. (2001). Microbial decolourisation and degradation of textile dyes. Appl. Microbiol. Biotechnol., 56, 81-87.

[17] Fu, Y, \& Viraraghavan, T. (2001). Fungal decolorization of dye wastewaters: a review. Bioresour. Technol., 79, 251-262.

[18] Stolz, A. (2001). Basic and applied aspects in the microbial degradation of azo dyes. Appl. Microbiol. Biotechnol., 56, 69-80.

[19] Pereira, M. F. R, Soares, S. F, Orfao, J. J. M., \& Figueiredo, J. L. (2003). Adsorption of dyes on activated carbons: influence of surface chemical groups. Carbon, 41, 811-821.

[20] Marco, A, Esplugas, S, \& Saum, G. (1997). How and why to combine chemical and biological processes for wastewater treatment. Water Sci. Technol., 35, 231-327. 
[21] Bhattacharyya, K. G, \& Sarma, A. (2003). Adsorption characteristics of the dye, Brilliant Green, on Neem leaf powder. Dyes Pigments, 57, 211-222.

[22] RaviKumar, M. N. V., Sridhari, TR, Bhavani, KD, \& Dutta, PK. (1998). Trends in color removal from textile mill effluents. Colorage, 40, 25-34.

[23] Dabrowski, A. (2001). Adsorption, from theory to practice. Adv. Colloid Int. Sci., 93, 135-224.

[24] Ruthven, D. M. (1984). Principles of adsorption and adsorption processes;. Wiley-Int;.

[25] Suzuki, M. (1997). Role of adsorption in water enviroment processes. Wat. Sci. Tech., 35, 1-11.

[26] Ramakrishna, K. R, \& Viraraghavan, T. (1997). Dye removal using low cost adsorbents. Water Sci. Technol., 36, 189-196.

[27] Babel, S, \& Kurniawan, T. A. (2003). Low-cost adsorbents for heavy metals uptake from contaminated water: a review. J. Hazardous Mater., 97, 219-243.

[28] Streat, M, Patrick, J. W, \& Perez, M. J. (1995). Sorption of phenol and para-chlorophenol from water using conventional and novel activated carbons. Water Res., 29, 467-472.

[29] Crini, G. (2006). Non-conventional low-cost adsorbents for dye removal: a review. Bioresour Technol., 60, 67-75.

[30] Rinaudo, M. (2006). Chitin and chitosan: properties and applications. Prog. Polym. Sci., 31, 603-632.

[31] Crini, G, \& Badot, P. M. (2008). Application of chitosan, a natural aminopolysaccharide, for dye removal from aqueous solutions by adsorption process using batch studies: a review of recent literature. Prog. Polym. Sci. , 33, 399-447.

[32] Crini, G, Martel, B, \& Torri, G. (2008). Adsorption of C.I. Basic Blue 9 on chitosanbased materials. Int. J. Environ. Pollut., 34, 451-465.

[33] Crini, G, Robert, C, Gimbert, F, Martel, B, Adam, O, De Giorgi, F, \& Badot, P. M. (2008). The removal of Basic Blue 3 from aqueous solutions by chitosan-based adsorbent: batch studies. J. Hazard. Mater., 153, 96-106.

[34] Gaffar, M. A, Rafie, S. M, \& Tahlawy, K. F. (2005). Preparation and utilization of ionic exchange resin via graft copolymerization of b-CD itaconate with chitosan. Carbohyd. Polym., 56, 387-396.

[35] Martel, B, Devassine, M, Crini, G, Weltrowski, M, Bourdonneau, M, \& Morcellet, M. (2001). Preparation and adsorption properties of a beta-cyclodextrin-linked chitosan derivative. J. Polym. Sci. A Polym. Chem., 39, 169-176.

[36] Shimizu, Y, Tanigawa, S, Saito, Y, \& Nakamura, T. (2005). Synthesis of chemically modified chitosans with a higher fatty acid glycidyl and their adsorption abilities for anionic and cationic dyes. J. Appl. Polym. Sci., 96, 2423-2428. 
[37] Chao, A. C, Shyu, S. S, Lin, Y. C, \& Mi, F. L. (2004). Enzymatic grafting of carboxyl groups on to chitosan-to confer on chitosan the property of a cationic dye adsorbent. Bioresour Technol, 91-157.

[38] Uzun, I, \& Guzel, F. (2006). Rate studies on the adsorption of some dyestuffs and pnitrophenol by chitosan and monocarboxymethylated(MCM)-chitosan from aqueous solution. Dyes Pigm, 118, 141-154.

[39] Prabaharan, M, \& Mano, J. F. Chitosan derivatives bearing cyclodextrin cavities as novel adsorbent matrices. Carbohyd. Polym., 63, 153-166.

[40] Jayakumar, R, Prabaharan, M, Reis, R. L, \& Mano, J. F. (2002). Graft copolymerized chitosan-present and status applications. Carbohyd. Polym., 62, 142-158.

[41] Kyzas, G. Z, Kostoglou, M, \& Lazaridis, N. K. (2010). Relating interactions of dye molecules with chitosan to adsorption kinetic data. Langmuir, 26, 9617-9626.

[42] El-Tahlawy, K. F, Gaffar, M. A, \& Rafie, S. (2006). Novel method for preparation of bcyclodextrin/grafted chitosan and it's application. Carbohyd. Polym. , 63, 385-392.

[43] Cestari, A. R, Vieira, EFS, dos Santos, AGP, Mota, JA, \& de Almeida, VP. (2004). Adsorption on of anionic dyes on chitosan beads. 1. The influence of the chemical structures of dyes and temperature on the adsorption kinetics. J. Colloid Interf. Sci., 280, 380-386.

[44] Gibbs, G, Tobin, J. M, \& Guibal, E. (2003). Adsorption of acid green 25 on chitosan: influence of experimental parameters on uptake kinetics and adsorption isotherms. J. Appl. Polym. Sci., 90, 1073-1080.

[45] Gibbs, G, Tobin, J. M, \& Guibal, E. (2004). Influence of chitosan preprotonation on reactive black 5 adsorption isotherms and kinetics. Ind. Eng. Chem. Res., 43, 1-11.

[46] Chiou, M. S, \& Li, H. Y. (2003). Adsorption behavior of reactive dye in aqueous solution on chemical cross-linked chitosan beads. Chemosphere, 50, 1095-1105.

[47] Chiou, M. S, Kuo, W. S, \& Li, H. Y. (2003). Removal of reactive dye from wastewater by adsorption using ECH cross-linked chitosan beads as medium. J. Environ. Sci. Health. A, 38, 2621-2631.

[48] Chiou, M. S, Ho, P. Y, \& Li, H. Y. (2003). Adsorption behavior of dye AAVN and RB4 in acid solutions on chemically crosslinked chitosan beads. J. Chin. Inst. Chem. Eng., 34, 625-634.

[49] Chiou, M. S, Ho, P. Y, \& Li, H. Y. (2004). Adsorption of anionic dye in acid solutions using chemically cross-linked chitosan beads. Dyes Pigm., 60, 69-84.

[50] Guibal, E. (2005). Heterogeneous catalysis on chitosan-based materials: a review. Prog. Polym. Sci., 30, 71-109. 
[51] Guibal, E, Mccarrick, P, \& Tobin, J. M. (2003). Comparison of the adsorption of anionic dyes on activated carbon and chitosan derivatives from dilute solutions. Sep. Sci. Technol., 38, 3049-3073.

[52] Chatterjee, S, Chatterjee, S, Chatterjee, B. P, Das, A. R, \& Guha, A. K. (2005). Adsorption of a model anionic dye, eosin $\mathrm{Y}$, from aqueous solution by chitosan hydrobeads. J. Colloid Interf. Sci., 288, 30-35.

[53] Kyzas, G. Z, \& Lazaridis, N. K. (2009). Reactive and basic dyes removal by sorption onto chitosan derivatives. J. Colloid Interf. Sci., 331, 32-39.

[54] Tien, C. (1994). Adsorption Calculation and Modeling. Boston: Butterworth-Heinemann;.

[55] Langmuir, I. (1916). The constitution and fundamental properties of solids and liquids. J. Am. Chem. Soc., 38, 2221-2295.

[56] Freundlich, H. M. F. (1906). Uber die adsorption in $10^{\circ}$ sungen. Z. Phys. Chem., 57, 385-471.

[57] Giles, C. H, D' Silva, A. P., \& Easton, I. A. (1974). A general treatment and classification of the solute adsorption isotherm. II. Experimental interpretation. J. Colloid Interf. Sci., 47, 766-778.

[58] Giles, C. H, Smith, D, \& Huitson, A. (1974a). A general treatment and classification of the solute adsorption isotherm. I. Theoretical. J. Colloid Interf. Sci., 47, 755-765.

[59] Ravi Kumar, M. N. A review of chitin and chitosan applications. 2000, React. Funct. Polym., 46, 1-27.

[60] Saha, T. K, Karmaker, S, Ichikawa, H, \& Fukumori, Y. (2005). Mechanisms and kinetics of trisodium 2-hydroxy-1, 1'-azonaphthalene-3,4',6-trisulfonate adsorption onto chitosan. J. Colloid Interf. Sci., 286, 433-439.

[61] Chiou, M. S, \& Li, H. Y. (2002). Equilibrium and kinetic modeling of adsorption of reactive dye on cross-linked chitosan beads. J. Hazard. Mater., 93, 233-248.

[62] Rudzinski, W, \& Plazinski, W. (2008). Kinetics of solute adsorption at solid/aqueous interfaces: searching for the theoretical background of the modified pseudo-first-order kinetic equation. Langmuir, 24, 5393-5399.

[63] Liu, Y, \& Shen, L. (2008). From Langmuir kinetics to first- and second-order rate equations for adsorption. Langmuir, 24, 11625-11630.

[64] Konstandopoulos, A. G, Vlachos, N, Kostoglou, M, \& Patrianakos, G. (2007). Proceedings of the 6th International Conference of Multiphase Flow; Leipzig,.

[65] Hitchcock, P. W, \& Smith, D. W. (1998). Implications of non-equilibrium sorption on the interception-sorption trench remediation strategy. Geoderma, 84, 109-120. 
[66] Mckay, G. (1985). The adsorption of dyestuffs from aqueous solutions using activated carbon: An external mass transfer and homogeneous surface diffusion model. AICHE J., 31, 335-339.

[67] Crank, J. (1975). The Mathematics of Diffusion. 2nd ed.; London: Oxford University Press;.

[68] Lazaridis, N. K, Karapantsios, T. D, \& Georgantas, G. (2003). Kinetic analysis for removal of a reactive dye from aqueous solution on to hydrotalcite by adsorption. Water Res., 37, 3023-3033.

[69] Larson, A. C, \& Tien, C. (1984). Multicomponent liquid phase adsorption in batch, Parts I \& II. Chem. Eng. Commun., 27, 339-379.

[70] Coates, J. I, \& Glueckauf, E. (1947). Theory of chromatography; experimental separation of two solutes and comparison with theory. J. Chem. Soc., 5, 1308-1314.

[71] Guibal, E. (2004). Interactions of metal ions with chitosan-based sorbents: a review. Sep. Purif. Technol., 38, 43-74.

[72] Smith, M. B, \& March, J. (2001). March's Advanced Organic Chemistry. 5th ed.; New York: John Wiley \& Sons Inc;.

[73] Guibal, E, Milot, C, \& Tobin, J. M. (1998). Metal-anion sorption by chitosan beads: equilibrium a kinetic studies. Ind. Eng. Chem. Res., 37, 1454-1463.

[74] Chu, K. H. (2002). Removal of copper from aqueous solution by chitosan in prawn shell: adsorption equilibrium and kinetics. J. Hazard. Mater., 90, 77-95.

[75] Smith, J. M. (1981). Chemical Engineering Kinetics. New York: McGraw-Hill;.

[76] Brugnerotto, J, Lizardi, J, Goycoolea, F. M, Argüelles-monal, W, Desbrières, J, \& Rinaudo, M. (2001). An infrared investigation in relation with chitin and chitosan characterization. Polymer, 42, 3569-3580.

[77] Yang, R. T. (1987). Gas separation by adsorption processes. Boston: Butterworths;.

[78] Wang, L, \& Wang, A. (2008). Adsorption properties of congo red from aqueous solution onto N,O-carboxymethyl-chitosan. Bioresour. Technol., 99, 1403-1408.

[79] Sakkayawong, N, Thiravetyan, P, \& Nakbanpote, W. J. (2005). Adsorption mechanism of synthetic reactive dye wastewater by chitosan. J. Colloid. Interf. Sci., 286, $36-42$. 
